\title{
RAZÕES PARA AGIR (OU COMO LEWIS CARROLL NOS AJUDOU A ENTENDER TAMBÉM OS RACIOCÍNIOS PRÁTICOS)
}

\author{
Marco Antônio Oliveira de Azevedo
}

RESUMO - Neste artigo, procuro extrair algumas conseqüências da lição de Lewis Carroll sobre a diferença entre premissas e regras de inferência no tocante aos raciocínios práticos. Meu questionamento dirige-se à clássica suposição formalista contida na famosa "Lei de Hume", a saber, a regra formulada, dentre outros, por Richard Hare, de que é logicamente impossível derivar-se uma conclusão moral prática apenas de premissas fatuais. Na primeira parte deste artigo, proponho que o leitor imagine-se numa situação hipotética, na qual adota uma postura evasiva mesmo diante de razões prima facie suficientes para tomar uma certa decisão. A situação apresentada é uma versão do "análogo prático", engenhosamente construído por G. F. Schueler, ao clássico paradoxo de Lewis Carroll, contido em sua conhecida e genial estória da disputa entre Aquiles e a Tartaruga, publicada originalmente na revista Mind, em 1895. Na segunda parte, relembro e brevemente analiso a fábula carrolliniana, comparando-a com a versão prática de Schueler, discutindo suas analogias e dessemelhanças. Na terceira parte, mostro como as duas estórias são capazes de nos ajudar a desvendar alguns malentendidos sobre o raciocínio prático e sobre suas imbricações com a ética, em especial, com a conhecida tese de que de fatos não derivamos normas. Pretendo mostrar como essa famosa tese é vítima do mesmo vício formalista denunciado por Lewis Carroll, a saber, que é fruto de entendimentos equívocos acerca dos papéis que podem ser desempenhados por uma norma em
ABSTRACT - In this article, I look for some consequences of the lesson of Lewis Carroll of the difference between premises and rules of inferences in practical reasonings. My complaint is against the classical and formalist supposition contained in the famous "Hume's Law", that is, the rule, formulated, beside others, by Richard Hare, that it is logically impossible to derive a practical moral conclusion from (and only from) factual premises. In the first part of this article, I will invite the reader to imagine himself in a hypothetical situation, where he adopts a evasive attitude even in face of prima facie and sufficient reasons for a certain decision. The situation is a version of the "practical analogue" ingeniously created by G. F. Schueler to the Lewis Carroll's classical story of Aquiles and the Tortoise, originally published in Mind, 1895. On the second part, I'll show how the two stories can help us in exposing some misunderstandings of practical reasonings and its implications for ethics, in special, with the famous thesis that from facts we cannot infer norms. I'll intend to show how this thesis is victim of the same formalist error exposed by Lewis Carroll, to wit, that it is a product of equivocal suppositions about the roles of norms in practical reasonings, that is, that, primarily, this norms, as practical rules, occur in arguments not as premises, but as special rules (or material rules) of inference. If my thesis would be correct, then the claim that we cannot infer "norms" from "facts" results, indeed, from a misunderstanding. In the last part, I'll show some

Professor de Filosofia no IPA, Porto Alegre, e Médico.

\begin{tabular}{|l|l|l|l|l|l|}
\hline VERITAS & Porto Alegre & v. 52 & n. 2 & Junho 2007 & p. 91-108 \\
\hline
\end{tabular}


um raciocínio prático, isto é, que, primariamente, normas, na condição de regras práticas, não figuram propriamente como premissas, e sim como regras especiais ou materiais de inferência. Se minha tese for verdadeira, então a alegação de que não podemos derivar "normas" de "fatos" resulta, na verdade, de um mal-entendido. Na última parte do artigo, destaco algumas outras confusões acerca do significado do termo 'dever' tal como esse termo é empregado usualmente em conclusões de raciocínios práticos. Numa referência a Stanley Cavell, sustentarei que o termo 'dever' serve-nos, nessa condição, de modo de apresentação do conteúdo das premissas que temos ou das razões que oferecemos para agir de uma certa maneira. Sendo assim, o termo 'dever', que usamos para apresentar a conclusão de um raciocínio prático, não pode ser interpretado, de maneira simplista (tal como fazem os defensores de visões kantianas sobre a ética), como tendo o mesmo sentido que o termo 'obrigação', cujo significado é mais estrito.

PALAVRAS-CHAVE - Razões práticas. Racionalidade prática. Raciocínios morais. Raciocínios práticos. Lewis Carroll. David Hume. other confusions about the meaning of the term 'ought', as used in conclusions of practical reasonings. Following Stanley Cavell, I'll sustain that the term 'ought' is used, in this cases, as a mode of presentation of the content of the premises we have (or of the reasons we have) to act in a certain way. The term 'ought', as used to present the conclusion of a practical reasoning, cannot be interpreted, in a simplistic manner (in the way done by the supporters of a kantian conception of ethics), as having the same meaning of the term 'obligation' (that have a more rigorous meaning).

KEY WORDS - Practical reasons Practical rationality. Practical reasonings. Lewis Carroll. David Hume.

If a man have a lively sense of honour and virtue, with moderate passions, his conduct will always be conformable to the rules of morality; or if he depart from them, his return will be easy and expeditious. On the other hand, where one is born of so perverse a frame of mind, of so callous and insensible a disposition, as to have no relish for virtue and humanity, no sympathy with his fellow-creatures, no desire of esteem and applause; such a one must be allowed entirely incurable, nor is there any remedy in philosophy.

David Hume

Hume D. 'The sceptic' (1742), em Essays, p. 169

- Qualquer coisa que a Lógica me diga é digna de ser anotada - disse a Tartaruga. Lewis Carroll

\section{I}

Imagine que uma senhora septuagenária precisa atravessar uma avenida para chegar ao hospital onde espera fazer uma consulta de urgência. Chove torrencialmente, a avenida é bastante movimentada e não há passarelas. Mesmo com a faixa de segurança para pedestres, a travessia é difícil, pois a avenida é larga e os carros circulam velozmente. A senhora caminha muito lentamente e com certa dificuldade, e é bastante provável que não consiga atravessar a rua sem auxílio. Você também está prestes a atravessar no mesmo ponto, e não seria nada difícil auxiliá-la, bastando para isso estender sua mão em direção aos carros a fim de pará-los, para então escoltar a senhora até o outro lado da rua. Isso não lhe custa- 
ria muito, talvez apenas alguns minutos. Você não está com pressa e tem saúde suficiente para, mesmo num dia de chuva, parar o tráfego e ajudar a velhinha.

Suponhamos, porém, que, apesar de estar plenamente ciente de todos esses fatos, você atravesse a avenida e não ajude a velhinha. Mas antes que alguém o acuse de incoerência, você se adianta e, conhecendo um pouco de filosofia, cita Hume e lembra que "razões", por si mesmas, são incapazes de levar alguém a agir. ${ }^{1}$ E antes também que outra pessoa possa acusá-lo de irracionalidade, você também se adianta e lembra que há uma diferença fundamental entre dar justificativas e estar motivado a agir. Você admite que as relações entre razões e ações são normativas; todavia, alega que agir ou não com base nessas razões, ou que submeter-se a tais "relações normativas" não é algo que compete propriamente à razão resolver. Isto é, mesmo que houvesse alguma relação normativa que eventualmente tornasse tais fatos razões para agir, que ainda assim caberia a questão de querer-se ou não agir segundo elas, ou de sentir-se ou não submetido a elas, particularmente neste caso. E, em sendo assim, conclui que, como não há nada prima facie de irracional em sua conduta, que não faz sentido criticar sua omissão. Afinal, diz, 'quem deve decidir sou eu!' E se alguém tentar mostrar que sua conduta não é apenas irracional, mas substancialmente imoral, você retorna ao mesmo ponto e alega que nenhuma razão, mesmo moral, por si só, exige ou é capaz de motivar alguém a adotar uma conduta qualquer. O que parece deixá-lo à vontade para dar as costas à pobre velhinha.

Contra esse ponto de vista, há uma queixa dirigida pelos defensores do que chamarei de internalismo de razões (IR). Para o defensor do IR, estar ciente do conjunto de fatos que constituem razões para ajudar a velhinha acarreta estar ciente da obrigação de ajudá-la nessas circunstâncias. E também, segundo o IR, não faz sentido afirmar que alguém possa reconhecer que está diante de uma obrigação e (ainda) não estar suficientemente motivado para agir. ${ }^{2}$ Com efeito, segundo essa visão, estar racionalmente ciente de um dever (entendido, sempre, como uma obrigação) acarreta, igualmente, a existência de um motivo (suficiente) para agir. Deixar de cumprir um dever de que se tem ciência (em sentido racional) somente poderia ser explicado ou justificado por outras razões ou deveres maiores. Nesse caso, porém, a maioria dos defensores desse tipo de internalismo consideram que passamos a estar submetidos a um dever atual ou efetivo que sub-roga ou anula os deveres anteriores (deveres que deixam de ser, com efeito, atuais). ${ }^{3}$

\footnotetext{
'[R]eason alone can never produce any action, or give rise to volition'. HUME, D. Treatise of human nature, p. 414

O que não faz sentido, para o defensor de IR, portanto, é afirmar que a seguinte conjunção pode ser verdadeira: "A acredita que está obrigado a Ø' \& 'A não está motivado a Ø" (onde Ø está para uma ação de A que expressa a conclusão correta de um raciocínio prático).

3 Bernard Williams referiu-se (criticamente) a essa visão como sendo a de que somente uma obrigação pode "bater" uma outra obrigação (ver: WILLIAMS, B. Ethics and the limits of philosophy, p. 180-1). A essa visão Williams associou a idéia de um "princípio", que intitulou "the obligation-out, obligation-in principle', típico aos sistemas de moralidade, que, no contexto deste ensaio, são objeto da defesa dos partidários do IR.
} 
Os argumentos a favor do IR são sofisticados e não me aterei a eles neste artigo. ${ }^{4}$ Por ora, interessa-me destacar que o IR é incapaz de modificar o panorama anterior. Pois você poderia simplesmente admitir que aceita que estar ciente de certos fatos e razões para agir equivale a estar ciente do dever de fazer algo. Todavia, o que você poderia "humeanamente" continuar alegando é que estar ciente de um dever para agir não equivale a estar suficientemente motivado a agir; ou que estar ciente de um dever não é, ou talvez ainda não seja um motivo suficiente para levá-lo a agir, o que poderia levá-lo a afirmar algo, enfim, ainda mais "radical", a saber, que, de fato, nenhuma razão por si só é capaz de motivar uma ação qualquer (sua ou de qualquer outrem).

Diante dessas evasivas, o internalista de razões, preso à tese de que o que conduz uma pessoa racional a agir são deveres ou obrigações de que se está simplesmente ciente, insiste coerentemente em fornecer-lhe novos argumentos, na intenção de fazê-lo vislumbrar algo de que talvez você não tenha, quiçá por algum desleixo, se dado conta. Procura, assim, mostrar-lhe como certas premissas adicionais explícitas são capazes de tornar seu argumento logicamente poderoso. Imagina, com isso, que a força racional de seu argumento o conduzirá, não somente a reconhecer um dever de agir, mas que, dado que você é uma pessoa racional, o levará efetivamente a agir do modo indicado. Entretanto, retornando a seu ponto de vista "humeano", isso pode continuar não modificando em nada a sua disposição anterior, já que sua posição era exatamente a de que nenhuma imposição lógica ou cognitiva, por si só, é capaz de exigir-lhe qualquer conduta. Chamemos a esse paradoxo de paradoxo cético ou niilista sobre razões práticas.

Bem, há de fato evidências aparentemente derradeiras em favor da tese de que razões ou crenças não são motivadoras o suficiente para agir. Há pessoas que agem com freqüência e mesmo sistematicamente, por impulso. Há outras que

${ }^{4}$ O que chamo de 'internalismo de razões' coincide com as teorias que Darwall, Gibbard \& Railton classificaram de 'teorias do raciocínio prático' de orientação kantiana, representadas, entre outros, por Thomas Nagel, Alan Donagan, Cristine Korsgaard, Alan Gewirth e o próprio Stephen Darwall. Segundo Darwall, Gibbard \& Railton, para essas teorias 'o que se precisa em ética é a idéia de uma razão válida para agir, em oposição à idéia de uma razão para crer, tal como se opera nas disciplinas teóricas' (DARWALL, S., GIBBARD, A., \& RAILTON, P. 'Toward fin de siècle Ethics: some trends', p.131). Darwall classificou essas teorias como internalistas, fazendo uma útil diferenciação entre internalismo de razões e internalismo de motivos (DARWALL, S. The british moralists and the internal 'ought'). Os teoristas da razão prática seriam, com efeito, internalistas de razões. Minha designação internalismo de razões tem, porém, uma finalidade estrita. Refiro-me às teorias que consideram, primeiro, que todo raciocínio moral é um raciocínio prático no qual se acham encadeadas razões e ações (no sentido igualmente de que raciocínios morais nunca conduzem a crenças, e sim sempre a ações), e, segundo, que estas ações ou conclusões práticas expressam deveres entendidos como obrigações práticas acarretadas por aquelas razões. Com essa designação (IR), busco referir-me, portanto, especialmente às teorias "kantianas" (embora existam defensores da mesma concepção geral, especialmente da que assimila raciocínios morais a raciocínios práticos, que se amparam, todavia, não propriamente em Kant, mas em outros autores clássicos bastante distantes de Kant, como Hobbes e Aristóteles, por exemplo). Judith Jarvis Thomson, a propósito, identificou nessas concepções uma característica comum que chamou de uma visão simplificadora sobre razões morais práticas, isto é, a visão de que 'uma consideração moral somente pode ter força sobre nós apenas, caso acarrete que uma pessoa deva fazer tal coisa' (THOMSON, J. J. The realm of rights, p. 84-5). 
agem intencionalmente contra o que a moralidade prega, seja excepcionalmente, seja sistematicamente (alguns, por exemplo, por evidente perversidade). ${ }^{5}$ Pessoas usualmente racionais podem também, ao menos eventualmente, tornar-se sensíveis a motivações irracionais, motivações, portanto, que elas julgam ou seriam capazes de julgar irracionais. E tais motivações ocasionais, mesmo que persistentes, e ainda que dificilmente "sistemáticas", não precisariam sequer ser propriamente inconscientes. ${ }^{6}$

Tais fatos "psicológicos" serviriam ao niilista como evidências empíricas em favor de sua posição de que não há uma conexão necessária entre razões de que se está ciente, e ações, entendidas supostamente como obrigatórias, ou por tais razões, acarretadas.

Porém, há algo desolador nesse panorama. Pois ele parece nos conduzir a um cenário niilista no qual as conexões entre razões e motivações figurariam apenas como conexões acidentais e subjetivamente variáveis. De fato, sequer poderíamos dizer do niilista que ele está errado, ou que age em vício. Afinal, não havendo qualquer conexão conceitual ou interna entre razões e ações, como chegaríamos a um mesmo entendimento sobre nossos juízos? De fato, nesse caso, quaisquer conexões "acidentais" servem para "justificar" uma ação (ou omissão) - de fato, se admitirmos a alegação cética, não faz sentido sequer falar em justificativas.

Em filosofia moral, sempre se sustentou a expectativa, fortemente alegada pelos chamados "teoristas do raciocínio prático" (para usar uma expressão de Stephen Darwall), dentre os quais, os defensores do IR, de que a função principal da moralidade é guiar as ações das pessoas. ${ }^{7}$ Mas, se a conexão entre razões e motivos for apenas algo acidental, se não pudermos mostrar que há uma conexão necessária, lógica, entre razões morais e ações, então, assim pensam os defensores do IR, a ética, quando muito, não passaria de mera especulação, de um conjunto, portanto, de crenças sem qualquer conexão ou efeito sobre a vida prática. Que razões, enfim, teríamos contra o sujeito imoral que, inacessível a argumentos, prende-se à conclusão de que nenhuma razão por si só é capaz de motivar alguém, inclusive e talvez especialmente a ele, a agir? Afinal, dizem, se não há conexões entre razões morais e ações, não faz sentido igualmente criticar sua conduta.

5 Estou considerando, por ora, apenas a possibilidade de atitudes contrárias à moralidade, todavia, irracionais, e contrárias, portanto, a qualquer perspectiva racional de auto-realização. Contudo, o que diríamos, por outro lado, de Nietzsche, o qual alegava que as imposições da moralidade são prejudiciais aos homens de valor? Segundo Nietzsche, a moralidade, que ele entendia como um sistema de normas próprias aos homens "escravos", era imprópria aos "nobres", os quais, limitados por tais restrições morais, tornam-se, de fato, impedidos de realizar seus potenciais individuais.

6 Veja-se o exemplo de alguns "vícios" bastante comuns, como o tabagismo. É perfeitamente possível que uma pessoa esteja suficientemente convencida dos males do cigarro, seja uma pessoa racional e inteligente, e ainda assim seja incapaz de parar de fumar, isto é, de parar de fazer algo contrariamente a suas melhores razões.

Sobre essa conexão "essencial" entre razões morais e razões práticas, veja-se, por exemplo, o clássico de Stephen Toulmin, An examination of the place of reason in ethics. Uma boa visão sobre a praticabilidade da ética é dada por John Finnis, em suas Carroll Lectures, de 1982 (FINNIS, J. Fundamentals of ethics, p. 1-25) 
Hume é tido como um defensor desse tipo de subterfúgio cético cuja conseqüência seria uma forma sofisticada de niilismo moral. Penso que essa interpretação deve-se, na verdade, a um grande mal-entendido. ${ }^{8}$ Afinal, Hume sempre tomou o ceticismo como uma posição insustentável. Argumentos céticos, como vimos, serviram para Hume apenas como técnicas de redução ao absurdo das doutrinas filosóficas que ele criticava. Para Hume, portanto, posições céticas são insustentáveis no domínio prático. O que é ainda pior, em se tratando de assuntos morais, pois, se é verdade que o cético, em filosofia especulativa, assume posições apenas ridículas, em filosofia moral, assim pensava Hume, ele assume posições bem mais perigosas e intoleráveis. ${ }^{9}$

É mais plausível (e caridoso) admitir, portanto, que, para Hume, o ceticismo, e seu congênere em filosofia moral, o niilismo, somente podem ser levados a sério como um modo de redução ao absurdo de certas pretensões especulativas ou abstratas, chamando-nos, com efeito, a atenção para a necessidade de um conhecimento da natureza humana ancorado na ciência experimental, já que teorias morais incapazes de explicar a ação humana somente justificariam as ações de anjos e outros seres perfeitos. Essas teorias justamente não cumpririam a exigência de praticidade ou praticabilidade da ética em que tanto insistiram os antigos. O paradoxo cético talvez nos permita, assim, identificar certas falhas congênitas com certas formas tradicionais ou vulgares de argumentação, morais, religiosas ou metafísicas. A esse diagnóstico corresponderia uma certa terapêutica, ou solução cética adequada. Aliás, esse era, de fato, o projeto filosófico que impulsionou Hume. ${ }^{10}$

O problema com as tradicionais teorias morais deontológicas que seguem o IR é que elas são presas fáceis do paradoxo, tal como pequenos animais inocentes presos à armadilha de um astuto predador. Com isso, tais visões acabam, inadvertidamente, fornecendo alimento ao nilismo. Foi essa limitação argumentativa que tornou os precursores modernos do IR (de Samuel Clarke a Kant) alvos fáceis para a ironia sutil de filósofos como Hume e Nietzsche, os quais pretendiam, por vias embora algo diversas, desvencilhar-nos dessas armadilhas céticas. ${ }^{11}$

8 Essa foi uma de minhas principais alegações em minha tese de doutorado (AZEVEDO, MAO. A "lei de Hume". Investigação sobre o naturalismo moral, 2003).

- Em verdade, nem mesmo os céticos pirrônicos (Sexto Empírico, por exemplo) eram defensores desse tipo de ceticismo radical que Hume tinha em vista em suas críticas e ironias. Talvez a crítica valha mais para os céticos dogmáticos e os modernos (veja-se, a propósito, a crítica de Porchat à visão de Hume sobre os céticos, em Vida comum e ceticismo, p. 174).

10 Tal como defendi, a propósito, em minha tese de doutoramento (op. cit.).

${ }^{11}$ Hume criticou Clarke e os demais filósofos racionalistas de seu tempo, assim como Nietzsche tomou Kant (e Schopenhauer) como seus adversários. Sobre o naturalismo em Nietzsche e sobre sua oposição ao deontologismo moral veja-se o belo artigo de Brian Leiter, 'Nietzsche and the morality critics'. 
A situação prática e hipotética que esbocei acima copia, em linhas gerais, uma versão pouco conhecida de G. F. Schueler à célebre parábola criada por Lewis Carroll, uma espécie de análogo prático à conhecida estória carrolliniana, na qual a esperta Tartaruga consegue envolver o ingênuo Aquiles numa surpreendente regressão ao infinito. ${ }^{12} \mathrm{Na}$ fábula de Lewis Carroll, a Tartaruga deixa Aquiles atônito, ao levá-lo incansavelmente a acrescentar indefinidamente novas premissas a seu argumento, na expectativa ardilosa de frustrar a ingênua suposição inicial do lendário corredor grego de que apenas alguns passos formais seriam suficientes para estabelecer a validade de certa conclusão matemática (no caso, a primeira proposição de Euclides sobre o triângulo eqüilátero). Para relembrar, aqui vai um pequeno resumo.

Na fábula carrolliana, a Tartaruga pede que Aquiles transcreva para seu caderno de anotações duas proposições que correspondem a uma etapa do argumento para provar a conhecida primeira proposição de Euclides, mais uma conclusão que se poderia tirar delas:

(A) Duas coisas que são iguais a uma terceira são iguais entre si.

(B) Os dois lados deste triângulo são iguais a um terceiro.

(Z) Os dois lados deste triângulo são iguais entre si.

Dado que $Z$ é uma conseqüência lógica de $A$ e $B$, alega-se que qualquer um que considerasse $A$ e $B$ verdadeiras deveria igualmente aceitar $Z$ como verdadeira. Logo, mesmo que alguém não aceitasse a verdade de $A$ e $B$, ele deveria ao menos aceitar como verdadeira, por motivos exclusivamente lógicos, a seguinte proposição hipotética:

(C) Se $A$ e $B$ forem verdadeiras, então $Z$ deve ser igualmente verdadeira.

Imaginemos, porém, alguém que aceitasse a verdade de $A$ e $B$, mas não aceitasse a verdade da proposição hipotética $C$. Nesse caso, ele não notaria que $Z$ deriva-se de $A$ e $B$. Mas se aceitasse $C$, assim supõe Aquiles na fábula, então ele estaria forçado a aceitar $Z$ (a lógica, diz Aquiles na parábola, 'o pegaria pelo pescoço'). Mas, então, não bastaria provar a verdade das proposições $A$ e $B$, para conduzir o interlocutor a aceitar $Z$. Seria preciso pedir que aceitasse igualmente $C$, pois, se ele aceitar $C$ (tendo aceito $A$ e B), logicamente deverá aceitar $Z$.

Assim procede Aquiles. Mas antes que a lógica o pegue pelo pescoço, a Tartaruga, sábia e ardilosamente, pede a Aquiles que escreva isto em seu caderno de anotações, já que se trata, afirma ela, obviamente, de uma nova proposição hipotética:

${ }^{12}$ SCHUELER, G. F. "Why 'oughts' are not facts"; CARROLL, Lewis, 'What the Tortoise said to Aquiles'. 
(D) Se $A, B$ e $C$ são verdadeiras, $Z$ deve ser verdadeira.

Eis que a astúcia da Tartaruga acaba por envolver o obtuso Aquiles em uma armadilha lógica, pois, ao tornar $D$ uma nova proposição hipotética, Aquiles vê-se logicamente conduzido a uma regressão ao infinito. Pois, seguindo no mesmo curso, ele se vê instado a pedir que $D$ seja aceita, pois, se alguém aceitar $D$ (tendo aceito $A, B$ e $C$ ), então logicamente não poderá não aceitar $Z$. $O$ que redunda numa nova proposição hipotética $E$, e, assim, indefinidamente. A desistência de Aquiles em prosseguir em sua vã empresa de que a lógica pudesse agarrar a Tartaruga pela goela, forçando-a a aceitar $Z$, leva-o, ao final, a um último e patético comentário irônico: a antes sábia e respeitada Tartaruga é vista agora como nada mais que uma perversa torturuga. ${ }^{13}$

Schueler apresentou seu "análogo prático" em uma conferência comemorativa ao centenário da publicação da parábola de Lewis Carroll, realizada em julho de 1995, na Universidade de Glasgow. Suponhamos, pede ele, que uma senhora de idade, chamada Mrs. Ganderhoot, que se encontra prestes a atravessar uma rua de intenso movimento, se dirigisse a você, fazendo as seguintes considerações:

(a) Ela quer e precisa atravessar a rua, a fim de buscar o cheque de pagamento de sua mísera pensão, algo absolutamente necessário para sua sustentação durante a semana.

(b) Está frio e chove torrencialmente.

(c) O tráfego está intenso.

(d) A senhora Ganderhoot é uma frágil e tímida velhinha, que certamente ficará parada à beira da calçada durante os próximos seis meses, a menos que alguém venha ajudá-la a atravessar a rua.

(e) Você está prestes a atravessar a rua a caminho da biblioteca.

(f) Você poderia muito facilmente ajudar a senhora Ganderhoot a atravessar a rua, simplesmente erguendo sua mão, a fim de parar o tráfego, escoltando-a durante a travessia.

(g) Ajudá-la assim não lhe custará nada, nem dinheiro extra, nem aumentará suas chances de ser atropelado, etc.

Porém, em que pese todas essas considerações, você não dá sinais de ajudála, e apenas indica-lhe que siga andando entre os carros. A senhora Ganderhoot, então, assinala-lhe que os fatos acima dão sustentação (embora, entendendo algo de lógica, admita que propriamente não acarretam) à conclusão de que:

(h) Você deve ajudá-la a atravessar a rua nessas circunstâncias.

${ }_{13}$ 'Torturuga' é o trocadilho utilizado por Sebastião Uchoa Leite, um dos tradutores da fábula de Carroll para o português. 
Suponhamos que você esteja disposto a enfrentar o desafio lógico posto pela senhora Ganderhoot. Você retorna, então, ao meio-fio e lhe diz que certamente concorda com os fatos que ela lhe apresentou na intenção de sustentar a afirmação de que você deve ajudá-la a atravessar a rua em tais circunstâncias. Porém, após dizê-lo, você lhe dá novamente as costas e desce a calçada, pronto para aproveitar o melhor momento e atravessar a rua. Se isso nos deixaria perplexos, imagine então a Senhora Ganderhoot. Deve haver, pensa ela, algum outro motivo circunstancial, que talvez ela desconheça, e que o impeça efetivamente de ajudála. Você, então, lhe assegura que não há nenhum outro motivo, ao que ela reafirma sua convicção de, em não havendo outro motivo significativo, e sendo as coisas assim (caeteris paribus), tal como já foram acima descritas, que você tem o dever de ajudá-la a atravessar a rua.

Diante disso, você diz que também concorda que

(i) já que não há nenhuma outra razão para que não a ajude, que você tem o dever de ajudá-la a atravessar a rua em tais circunstâncias.

A senhora Ganderhoot, apesar da chuva, sabiamente anotou, à semelhança de Aquiles, cuidadosamente todos os passos do seu argumento. Todavia, mesmo assim, você dá sinais de que não a ajudará a atravessar a rua, ao que ela pergunta se há alguma outra vantagem ou benefício que você obteria, caso atravesse a rua, sem ajudá-la (uma vantagem financeira, etc.). Você novamente lhe repete que não se trata disso, e que também pode aceitar a verdade de uma nova proposição:

(j) Desde que não há nenhuma razão para não ajudá-la, consideradas todas as razões, que você deve ajudá-la a atravessar a rua.

Ao terminar de enunciar (j), surge uma boa oportunidade de fazer a travessia, o que você aproveita sem cerimônias, deixando a pobre velhinha atônita na calçada, sem tempo sequer de pronunciar uma única palavra a mais.

Diante de um caso assim, eu não teria dúvidas em afirmar que você é, no mínimo, um sujeito insensível. Mas, insensível a quê? Às razões da senhora Ganderhoot? Se é isso, então, onde foi que ela errou? Pois, dado que você é uma pessoa racional, isso significa dizer que você é insensível a suas próprias razões? A senhora Ganderhoot, em algum sentido, supôs exatamente isso: que você provavelmente não se deu conta de algum aspecto importante de seu próprio argumento. Uma pessoa racional não poderia deixar de aceder praticamente a uma razão com a qual concorda, especialmente se de fato é uma boa razão.

Schueler analisa a estratégia da senhora Ganderhoot, seguindo o que vem sendo dito em torno do erro de Aquiles nos debates que se seguiram à primeira publicação da parábola de Lewis Carroll, em 1895.

Primeiro, Aquiles teria errado, ao pensar que, adicionando as premissas hipotéticas $C, D, E$, etc., ao grupo inicial de premissas, estaria fortalecendo seu argu- 
mento (no sentido de, quanto maior o conjunto de evidências, mais forte o argumento).

Segundo, que seria um erro de Aquiles supor que, dado que a Tartaruga havia aceito $A$ e $B$, tudo o que necessitava, ao ser questionada se aceitaria $Z$, era aceitar $C$; ou melhor, se para ela já era razoável (no caso, logicamente razoável) aceitar $A$ e $B$, para aceitar $Z$, a única coisa que faltava era aceitar que $A$ e $B$ acarretam $Z$. Ora, há uma diferença entre o que é formulado em $C$ ('se $A$ e $B$ são verdadeiras, $Z$ deve ser verdadeira'), que meramente diz que $Z$ é uma conseqüência lógica de $A$ e $B$, e a exigência de que 'Se a Tartaruga aceita $A$ e $B$, então ela deve aceitar $Z$ ', pois esta última exigência é acerca do que é racionalmente requerido para aceitar $Z$, o que poderia ser falso, mesmo que $C$ fosse aceita; isto é, poderia ser falso para alguém que $A$ e $B$ são razões para crer em $Z$, mesmo aceitando a proposição hipotética: se $A$ e $B$ são (ou fossem) verdadeiras, $Z$ deve (ou deveria) ser verdadeira. Logo, empregar uma proposição hipotética como premissa em um argumento não cumpre a mesma função normativa da regra ou princípio que valida ou autoriza um argumento. Interpretá-la como premissa é decididamente não interpretá-la como regra!

Schueler destaca ainda uma terceira confusão de que Aquiles foi vítima. Mesmo que seja razoável para a Tartaruga aceitar $Z$ (seja porque $Z$ é acarretada por coisas que a Tartaruga acredita, seja porque ela tem pouca ou nenhuma razão para descrer delas, etc.), as pessoas (e certamente tartarugas carrollinianas) algumas vezes deixam de crer em coisas que deveriam racionalmente crer. Isso pode ocorrer por mera falta de inteligência, desatenção, etc. E essas "falhas" podem ser em algum sentido "motivadas". As evidências podem estar todas à disposição, claramente à vista, mas aceitar uma certa conclusão pode ser prejudicial à minha teoria sobre o comportamento dos bichinhos e das tartarugas, ou à reputação de um amigo, etc., de modo que 'eu simplesmente não posso aceitar o que isso implica'. ${ }^{14}$

Comparando as duas estórias, há, por certo, diferenças que merecem consideração. Primeiro, enquanto Aquiles busca levar a Tartaruga a crer em alguma coisa, a senhora Ganderhoot busca levá-lo a fazer alguma coisa. Tradicionalmente se diria que o diálogo entre Aquiles e a Tartaruga se estabelece no domínio da razão teórica, ao passo que o que foi protagonizado pela senhora Ganderhoot sucede-se no domínio da razão prática. Segundo, Aquiles procura conduzir a Tartaruga a adotar uma atitude proposicional, ao passo que a senhora Ganderhoot tenta con-

14 SCHUELER, G. F. "Why 'oughts' are not facts", p. 717. Bernard Williams insistiu num ponto semelhante contra as teorias deontológicas sobre a moralidade ao alegar que "obrigações morais" podem eventualmente contrariar projetos e compromissos pessoais que o agente pode não estar disposto a abandonar (WILLIAMS, B. Ethics and the limits of philosophy). O mesmo foi defendido por Susan Wolf em seu clássico 'Moral saints', de 1982. Isso significa dizer que a "falha" em não adotar um certo curso de ação, dadas certas razões, deve-se a uma certa concepção sobre o que é requerido, uma certa concepção sobre o que efetivamente pode contar como uma razão para agir, que pode eventualmente contrariar certas convicções pessoais do agente. Williams entende que fica difícil entender por que razão alguém abandonaria, nesses casos, suas convicções pessoais para agir segundo razões que não o tocam de um modo mais íntimo. 
duzir alguém a fazer algo, no caso, a ajudá-la a atravessar a rua. Isto é, uma ação que, como tal, não teria propriamente conteúdo proposicional.

Essas quebras de analogia não são irrelevantes; não obstante, há razões para questioná-las. Afinal, também faz sentido dizer que tanto Aquiles como a senhora Ganderhoot procuram conduzir alguém a "fazer" alguma coisa, e que o fazem procurando motivá-lo, talvez ingenuamente, por meio de razões. Aquiles tenta convencer a Tartaruga a adotar uma atitude, a ter uma crença, ao passo que a senhora Ganderhoot procura persuadir alguém a auxiliá-la. Com isso se questiona a "profundidade" da distinção tradicional entre raciocínios teóricos e raciocínios práticos. Essa é uma idéia central para Schueler, pois, 'nos dois casos, os argumentos apresentados são argumentos para se fazer alguma coisa, para adquirir uma certa crença ou para realizar uma certa ação'. ${ }^{15}$

A diferença toda parece residir, portanto, no tipo de ato que é conclusão da inferência: se uma crença (seja uma atitude proposicional pensada ou externalizada na forma de uma asserção), ou uma ação propriamente dita. Porém, isso não afeta a analogia: ambos são exemplos de alguém que procura persuadir outrem a adotar uma certa conduta através de argumentos racionais. ${ }^{16}$

\section{III}

Stanley Cavell foi um dos que se rebelou contra a tese de que falta algo a uma crença, para que possa efetivamente tornar-se uma razão prática. Para Cavell, é estranho supor que o sentido de uma conclusão (seja o sentido da proposição que expressa uma crença, seja o sentido moral expresso por uma ação) somente possa ser alcançado mediante a elucidação de alguma outra razão que sirva como uma espécie de elo racionalizador na cadeia, uma premissa maior usualmente omitida em nosso discurso cotidiano. Pois, assim sustenta Cavell, em termos práticos, nada mais é preciso, além de nossas razões usuais, desde que, evidentemente, essas razões sejam verdadeiras (para o caso de raciocínios que buscam fornecer provas definitivas ou necessárias), ou, como ocorre na grande maioria dos casos, ao menos suficientemente verdadeiras (caso dos raciocínios, cujas conclusões não possam ser tomadas como conseqüências lógicas de suas evidências). Esse, aliás, era um dos erros de Aquiles, o primeiro dos assinalados por Schueler.

Um defensor de uma concepção formalista sobre argumentos (e penso que o IR é um exemplo) poderia assinalar, entretanto, que, no caso do diálogo com a senhora Ganderhoot, foi justamente a falta de uma norma geral o motivo pelo qual seus argumentos não obtiveram o efeito desejado, a saber, o de conduzir seu interlocutor a auxiliá-la a atravessar a rua. Mas qual poderia ser essa norma geral? Talvez uma versão universal da prescrição $h$, algo como:

SCHUELER, G. F. "Why 'oughts' are not facts", p. 718.

Austin diria que ambos são exemplos de alguém que procura obter efeitos perlocucionários, mediante ações ilocucionárias (que envolvem ações locucionárias). 
(u) Deve-se, em circunstâncias análogas, ajudar outra pessoa necessitada.

O que poderia ser interpretado como uma versão particular do chamado princípio da beneficência: ${ }^{17}$

(u') Deve-se, nas circunstâncias apropriadas, fazer coisas em benefício de outra pessoa necessitada.

Ou do princípio de benevolência: demais

(u') Deve-se, nas circunstâncias apropriadas, fazer o bem, e não o mal, aos

Um formalista poderia sugerir-nos o acréscimo desses princípios universais ao argumento da senhora Ganderhoot. A questão, agora, é ver se isso, de algum modo, fortaleceria seu argumento, fazendo-nos ver algo que as razões anteriores não nos permitiam vislumbrar.

Ora, isso nos remete novamente ao primeiro e ao segundo erros de Aquiles. Em seu diálogo com a Tartaruga, Aquiles é instado a adicionar uma premissa a seu argumento, na forma de uma proposição condicional hipotética, na intenção de chamar a atenção da Tartaruga para a regra que valida a inferência 'A e $B$, logo Z'. Isto é, talvez o objetivo de Aquiles fosse tão-somente fazer com que a Tartaruga pudesse vislumbrar que ela não poderia deixar de assentir a $Z$, caso aceitasse $A$ e $B$, se igualmente assentisse que se $A$ e $B$, então Z. Isso, talvez, na suspeita de que a Tartaruga possa não ter-se apercebido de que $A$ e $B$ acarretam $Z$. Teríamos um efeito persuasivo fundamental, que a levaria finalmente a admitir $\mathrm{Z}$ dado que aceita que $A$ e $B$ acarretam $Z$. No entanto, nada disso ocorre, mesmo porque esse efeito persuasivo ou psicológico, como tal, não é conseqüência lógica das premissas do argumento.

Schueler nos faz notar que também foram inúteis todas essas tentativas da senhora Ganderhoot de buscar em $i$ e $j$ argumentos adicionais em favor de $h$. Inúteis, tanto em termos lógicos como práticos. E o mesmo com respeito a meus adicionais $u$, $u^{\prime}$ e $u^{\prime \prime}$. Também não servem como reforço lógico ou prático os seguintes adicionais sugeridos por Schueler:

(h') Deve-se ajudar a senhora Ganderhoot, dado que a-g e $h$ são verdadeiros.

\footnotetext{
${ }_{17}$ William Frankena define o princípio de beneficência como 'o princípio segundo o qual devemos praticar o ato ou observar a regra que produzirá ou provavelmente virá produzir, no universo, a maior quantidade possível de bem em relação ao mal'. Frankena entende que esse princípio pressupõe outro, anterior, que ele chama princípio da benevolência, a saber, a obrigação prima facie de praticar o bem e evitar o mal (ver FRANKENA, Ética, p. 59).
} 
(h") Deve-se ajudar a senhora Ganderhoot, dado que a-g, $h$ e $h$ ' são verdadeiros.

E, assim, indefinidamente.

Com respeito a j, poderíamos, quem sabe, adicionar a premissa:

(j') Todas as premissas mostram que isso é, finalmente, o que devo fazer.

Porém, j' também é mais uma premissa a ser adicionada ao conjunto anterior, o que torna possível seguir indefinidamente:

(j") Todas as premissas, incluindo j', mostram que isso é, finalmente, o que devo fazer'.

Para Schueler, a moral da história é que, se há algum paradoxo exemplificado tanto na parábola carrolliniana, como em seu análogo prático, este é um paradoxo sobre a racionalidade em si, e não sobre um certo modelo especial de raciocínio (o teórico, ou o prático):

Os filósofos morais, que discutem a natureza de juízos sobre o que se 'deve' ou 'deveria' fazer (o que se 'precisa' é usualmente ignorado), geralmente tomaram esses juízos como dizendo respeito à moralidade, por vezes reconhecendo que juízos de prudência ou etiqueta podem ser igualmente formulados nesses termos. É quase universalmente tido por verdadeiro, entretanto, que tais juízos são sobre ações. Mas isso é um erro. Juízos sobre o que devíamos ou devemos fazer, ou mesmo sobre o que precisamos fazer, são feitos exatamente no mesmo sentido tanto sobre ações como sobre crenças, esperanças, temores e desejos. De fato, essas locuções aplicam-se a tudo o que podemos 'fazer' que é suscetível de crítica racional. O que tais juízos dizem é que a pessoa em questão tem alguma razão (decisiva, suficiente, etc.) para fazer, crer, esperar, ou temer seja o que estiver em questão. ${ }^{18}$

Com isso, Schueler pretende estar esclarecendo algo obscurecido pela visão geral de tomar o raciocínio prático como um tema especial da ética: 'deveres', como tais, não são 'fatos', não porque em ética raciocinaríamos praticamente e, "fora" da ética, na ciência, por exemplo, raciocinaríamos teoricamente. 'Deveres', tal como se emprega aqui, não são 'fatos', porque deveres, nesse aspecto, são regras inferenciais, e não premissas. Disso se segue, evitando as ambigüidades de nossa linguagem comum, que há vários tipos de "deveres": há regras que orientam o raciocínio sobre o que pode e o que não pode contar como conhecimento, sobre o que deve ou não deve ser acreditado, sobre o que pode e o que não pode ser justamente pensado; há regras que orientam a ação; e há regras (e por que não haveriam de existir) que orientam crenças relativamente a assuntos próprios à

18 SCHUELER, G. F. "Why 'oughts' are not facts", p. 722. 
ética, assim como também há regras (incluindo normas e princípios) que orientam ações moralmente recomendáveis, outras moralmente requeridas, e outras que são estritamente obrigatórias. Há uma confusão na filosofia moral em torno disso, e boa parte dos preconceitos contra a idéia de que se podem derivar conclusões morais de fatos deve-se a esse mal-entendido lógico desnudado por Lewis Carroll

\section{IV}

Há, porém, uma intenção honesta em boa parte dos filósofos morais do século $\mathrm{XX}$, de kantianos aos modernos internalistas de razões, a saber, a de poder provar que a razão prática nos conduz a ações necessárias ou obrigatórias. Que agir racionalmente, em termos éticos, equivale a motivar-se a agir (senão exclusivamente, ao menos primariamente) por razões universais (isto é, por razões que seriam aceitas como tais por qualquer sujeito racional, o que eliminaria a possibilidade de que razões egoístas não-universalizáveis pudessem contar como razões práticas em sentido próprio). Mostrar que essa equivalência é verdadeira é o que, afinal, motiva os internalistas de razões a defender o formalismo. Tendo em mente o análogo prático de Schueler, é na intenção de provar que a omissão em ajudar a senhora Ganderhoot é uma ação irracional que os internalistas de razões buscaram apoio no formalismo lógico (omitir-se em ajudá-la equivaleria a negar o dever de ajudá-la, o que implicaria, modus tollens, negar os fatos admitidos preliminarmente como verdadeiros, o que seria irracional). Porém, como parece plausível tomar o enunciado condicional cujo conseqüente é a conclusão prática, como uma proposição hipotética, resta ao internalista de razões mostrar que a conclusão prática segue-se de uma regra, a qual, admitida como hipotése, conduziria, dada a verdade dos fatos, a uma conclusão lógica, em nosso caso, de que se deve ajudar a velhinha. Todavia, essa estratégia continua infrutífera, pois tanto a parábola carrolliniana como o diálogo com a senhora Ganderhoot mostram-nos que nenhum acréscimo às premissas reforça, seja o argumento dedutivo de Aquiles, seja o argumento não-dedutivo da senhora Ganderhoot contra o cético ou contra o niilista moral. Não é isso, portanto, o que impede, nem a Tartaruga, nem o interlocutor da senhora Ganderhoot a esquivar-se de aceitar o argumento como decisivo. Contra o cético, portanto, resta-nos apenas a conclusão plausível de que já estávamos diante de uma prova aceitável (dedutiva ou indutiva), independentemente dos acréscimos sugeridos pela Tartaruga ou pela senhora Ganderhoot. Se é assim, então certamente não foi por ausência de "prova" que você se esquivou de ajudála. Hume diria (contra o IR) que o que o levou a deixar de reconhecer uma razão para agir, nos argumentos iniciais da senhora Ganderhoot, não foi sua irracionalidade, mas seu caráter. Ou seja, o que você teria deixado manifesto com sua atitude é a ausência de um certo tipo de disposição afetiva, a qual o tornaria apto, caso você a tivesse ao menos em certo grau, a inclinar-se a agir do modo indicado pela 
conclusão do argumento. ${ }^{19}$ Se estou certo, isso nos leva a questionar a tese internalista kantiana de que razões por si só são suficientes para motivar mesmo um sujeito racional a agir. ${ }^{20}$

De qualquer modo, estamos, portanto, diante de um paradoxo: um argumento convincente, em termos práticos, parece ser um argumento capaz de convencê-lo efetivamente a agir tal como sua conclusão exige; porém, ainda assim, continua sendo possível esquivar-se, mesmo diante de um de seus exemplos mais paradigmáticos. Diante desse paradoxo, uma das conclusões a que chegou Cavell foi que enunciados como $h$ não cumprem estritamente o papel de conclusões de inferências (isto é, que enunciados do tipo 'devo fazer $x$ ' não cumprem o mesmo papel lógico que as conclusões de raciocínios não-práticos). ${ }^{21}$ É provável, contudo, que Cavell tenha pretendido algo mais do que simplesmente desaconselhar uma analogia entre inferências cognitivas e raciocínios práticos. Não obstante, parece-me que Schueler, embora com outras palavras, disse algo parecido, pois, para ele, enunciados como $h$ apenas dizem que tenho uma razão para agir, e nada mais:

Quer dizer, $h$ não fornece ou descreve uma razão (do mesmo modo como, por exemplo, a o faz). Logo, $h$ não soma nada à força dos argumentos da senhora Ganderhoot. ${ }^{22}$

Penso que a sugestão de Cavell seria a de que tomássemos enunciados como h, no âmbito de discussões práticas, como as conduzidas pela senhora Ganderhoot, como modos de apresentação das razões dirigidas a um interlocutor como razões para que ele aja do modo indicado pela conclusão. ${ }^{23}$

19 Se tenho uma disposição ou traço de caráter que me torna apto a reconhecer nas razões da senhora Ganderhoot razões capazes de me motivar a agir, então não há qualquer necessidade de apresentar premissas adicionais a seu argumento. Isso porque as razões apresentadas já são razões suficientes. Bernard Williams, em defesa da visão sentimentalista humeana contra a visão racionalista dos kantianos, sustentou que se eu tenho um certo tipo de disposição adequada, então certos fatos podem ser desejados por mim como razões internas para agir; com efeito, os aspectos de um estadode-coisas desejado (relativos a uma outra pessoa) e que me motivam a agir, no sentido de promover a obtenção desse estado-de-coisas não são aspectos acerca de mim ou acerca de meus desejos, e sim aspectos relativos a essa pessoa. Sou motivado, portanto, pelo pensamento de que essa pessoa precisa de minha ajuda, e não pelo pensamento de que ela precisa de minha ajuda mais minha crença de que quero ou de que devo ajudá-la (a propósito, veja-se: WILLIAMS, B. Problems of the self, p. 265).

${ }^{20}$ Parece-me que um internalismo de motivos de tipo humeano torna-se, assim, uma alternativa bem mais plausível, pois não incorre nos mesmos vícios a que o formalismo conduz o internalista de razões.

${ }^{21}$ CAVELL, S. The claim of reason, p. 323. Cavell diz que o passo de razões práticas a uma prescrição do tipo 'Faça x' ou 'Você deve fazer x' não requer premissas maiores, pois não há nenhum hiato a ser preenchido.

22 SCHUELER, G. F. "Why 'oughts' are not facts", p. 720

${ }^{23}$ ' "Você deve ...' é, direi, embora não seja em nada diverso em conteúdo das premissas fornecidas em seu amparo e que exaurem seu conteúdo, um modo de apresentação desse conteúdo, um a que você tem de tomar posição a respeito' (CAVELL, The claim of reason, p. 318). Você tem de tomar posição a respeito, isto é: em se tratando de razões para crer, você está comprometido a posicionar, caso instado, sobre tanto; em se tratando de razões para agir, analogamente, você tem de tomar uma posição em termos práticos sobre o assunto. Observe-se, porém, que, nos dois casos (crenças e ações), você se encontra diante de algum compromisso racional (o de dever crer e o de dever agir). No primeiro caso, apresentamos nossa conclusão como sendo racional dizendo, por exemplo: 
Há outras particularidades nesses enunciados, e suspeito que elas possam jogar por terra a tese prescritivista tradicional ${ }^{24}$ de que enunciados como $h$, isto é, enunciados que expressem conclusões de argumentos práticos, devam ser interpretados, necessariamente, como sendo imperativos, isto é, que, em sentido estrito, expressam obrigações. Veja a seguinte alternativa:

(k) Será que você poderia me ajudar a atravessar a rua? ${ }^{25}$

O que não deixa também de ser um convite a uma tomada de posição com respeito à situação. Essa tomada de posição, dado seu contexto, tem certamente um sentido moral; porém, seu sentido não é assimilável à noção usual de estar moralmente obrigado, noção característica ao discurso dos prescritivistas. ${ }^{26}$ Parece-me também ser discutível que qualquer um estaria obrigado (em um sentido imperativo e objetivo) a ajudar a senhora Ganderhoot, mesmo dadas todas as razões e circunstâncias do caso ${ }^{27}$ Mais discutível ainda é a conclusão formalista de que $h$ somente conduziria alguém a agir, caso fosse possível mostrar que é uma conseqüência lógica tal obrigação de ajudá-la. Pois isso é justamente falso: a explicação para a decisão de ajudá-la nesse caso, e em casos similares, não depende da superação de um entimema. Além disso, mesmo que das razões de a a $g$ possamos inferir $h$, por dedução ou por indução, isso não implica que $h$ seja a única conclusão moral possível. Por exemplo, considere-se a conclusão de que, dadas as circunstâncias, seria bom ajudá-la, ou que seria um sinal de bondade ou virtude sua fazê-lo. É plenamente aceitável, nesse caso, que possa haver mais de uma boa alternativa a seguir-se, ainda que se possam classificar uma, ou algumas, como as melhores.

Isso me permite assinalar algo, a título complementar, sobre o tipo de conclusões que poderiam ser derivadas das razões indicadas pela senhora Ganderhoot. Pois é apenas sob um enfoque prescritivista que prescrições representam o único tipo de conclusão adequada em raciocínios práticos. ${ }^{28} \mathrm{O}$ assunto talvez não se reduza, como suporiam também os formalistas, a uma questão de aplicação de certa norma ou princípio universal do agir moral, mas a uma questão de cuidado e preocupação humanas. A senhora Ganderhoot, no caso, pode estar simplesmente

\footnotetext{
'é verdadeiro que ...' (poderia ser, também, 'afirmo que...', entre outras formas conhecidas), ao passo que, no segundo caso, dizemos: 'você deve fazer $x$ '. Ao realizarmos uma afirmação ou prescrevermos uma ação, estamos nos comprometendo com certas razões, indicando implicitamente que nosso interlocutor pode, caso deseje, instar-nos a indicá-las. A propósito dessa idéia, veja BRANDOM, R. Making it explicit.

Refiro-me especialmente a visões como as de Richard Hare (The language of morals, 1952).

Ou talvez: 'Seria gentil de sua parte ...', ou 'você poderia me dar uma ajuda?', etc.

${ }^{26}$ A propósito, veja-se o artigo de J. Gert, 'Practical rationality, morality and purely justificatory reasons'.

27 Vejam-se, a respeito, os argumentos de Judith Jarvis Thomson, eloqüentemente sustentada em seu famoso artigo 'A defense of abortion'.

28 Richard Hare é a principal referência da tese prescriptivista de que raciocínios morais são raciocínios, cujas conclusões são sempre prescriptivas (HARE, R. M., op. cit.).
} 
pedindo que lhe façam o que usualmente chamamos de uma gentileza (por certo, não uma gentileza qualquer, mas nem por isso uma exigência a que não se possa obviar por algum motivo racional qualquer, ou algum motivo de ordem moral). Imagine-se, diante do modo como a senhora Ganderhoot dirige-se a você expressando literalmente $h$ : 'Você está moralmente obrigado a me ajudar!', que você dê a seguinte resposta: 'Ei, você não pode dirigir-me ordens desse tipo, pode?' Ou, quem sabe algo menos grosseiro: 'A senhora está me pedindo um favor?' Penso que são respostas perfeitamente possíveis e até mesmo comuns, ainda que pouco respeitosas ou grosseiras. De qualquer modo, é uma prática comum de decoro responder com gentileza a pedidos razoáveis de "favores". Especialmente nas situações em que 'dever fazer algo' não é equivalente a 'estar sob um dever de fazê-lo' (no sentido de que podemos não estar sob nenhuma obrigação estrita, tal como a em que estamos diante dos direitos de outrem, e ainda assim reconhecer um "dever" em sentido "moral" de ajudar alguém). Trata-se de situações em que certas condutas não são propriamente exigidas, ainda que possam ser altamente recomendáveis. Parece, com efeito, claro que há uma diferença semântica e moralmente significativa entre recomendações morais e exigências ou obrigações morais. De fato, só obrigações autorizam alguém a dizer: 'Como é que você ainda não se deu conta de que está moralmente obrigado a me ajudar?'

Não é, portanto, adequado reduzir todos os tipos de interações humanas moralmente relevantes a expressões de um único tipo de dever, tal como sugerem as teorias éticas deontológicas. ${ }^{29}$ Isso significa que as mesmas razões, em circunstâncias distintas, podem amparar conclusões morais com um sentido normativo distinto. E mesmo que a apresentação de nossas razões morais possa ser feita, ao menos em quase todos os casos, conjugando um mesmo verbo auxiliar (o verbo 'dever'), isso não implica que todas as nossas conclusões morais sejam expressões de uma mesma noção normativa, isto é, que sejam expressões unitárias do que os filósofos deontologistas entendem por 'obrigação moral'. A palavra 'dever', na conclusão do argumento, pode ter apenas a função de indicar que certa proposição é a conclusão adequada de um raciocínio prático. É um dos modos de apresentação da conclusão de um argumento; e talvez seja esse, de fato, o modo geral de apresentação das conclusões de raciocínios práticos. Mas se o sentido do que se deve fazer é imperativo ou não, isso depende do tipo de regra de inferência ou conceito moral que autoriza a passagem de certas razões a uma conclusão prática. Ora, nem todas as noções e regras de inferência morais são noções ou regras imperativas. Confundir a regra que autoriza a inferência, com a função lógica (se quisermos, "modal") do termo 'dever', que apresenta ou indica a conclusão de um raciocínio prático, é uma das várias confusões a que fomos conduzidos pelos defensores das éticas deontológicas tradicionais.

${ }^{29}$ Um dos primeiros a insistir na distinção entre tipos de deveres foi G. J. Warnock, em The object of morality (p. 94s). 


\section{Referências}

AUSTIN, J. L. How to do things with words. Oxford Press, 1962.

AZEVEDO, M. A. O. A "lei de Hume". Investigação sobre o naturalismo moral. UFRGS, 2003.

BRANDOM, R. Making it explicit. Cambridge: Harvard UP, 1994

CARROLL, Lewis. "What the Tortoise said to Aquiles", Mind, 4, 1895, p. 278-80.

CAVELL, S. The claim of reason. Oxford UP, 1979.

DARWALL, S. The British moralists and the internal 'ought' (1640-1740). Cambridge: Cambridge UP, 1995.

DARWALL,S.; GIBBARD, A. \& RAILTON, P. 'Toward fin de siècle Ethics: some trends'. The philosophical review, vol. 101, n. 1, jan. 1992.

FINNIS, J. Fundamentals of ethics. Georgetown University Press, 1983.

FRANKENA, W. Ética. Rio de Janeiro: Zahar, 1969.

GERT, J. 'Practical rationality, morality and purely justificatory reasons'. American philosophical quarterly, vol. 37, n. 3, jul. 2000: 227-43.

HARE, R. M. The language of morals. Oxford UP, 1952 (traduzido para a língua portuguesa como: A linguagem da moral. São Paulo: Martins Fontes, 1996).

HUME, D. Treatise of human nature. Selby-Bigge, 2. ed. Oxford: Clarendon Press, 1978.

LEITER, B. 'Nietzsche and the morality critics'. Ethics, 107, jan. 1997: 250-285.

PORCHAT PEREIRA, O. Vida Comum e ceticismo. Editora Brasiliense, 1994.

SCHUELER, G. F. "Why 'oughts' are not facts". Mind, 1995: vol. 104.424, p. 713-23,

THOMPSOM, J. J. 'A defense of abortion'. Philosophy and public affairs, I(1), 1971:47-66. Republicado em: DWYER, S. \& FEINBERG, J. The problem of abortion. 3. ed., Wadsworth, 1977, p. 75-87 (traduzido para o português como: 'Uma defesa do aborto'. Filosofia política, nova série, vol. 2, Porto Alegre: L\&PM, 1998).

THOMSON, J. J. The realm of rights. Harvard Press, 1990.

TOULMIN, S. E. An examination of the place of reason in ethics, Cambridge: Cambridge U. P., 1964, 1. ed. de 1950

WARNOCK, G. J. The object of morality, Methuen \& Co Ltd., 1971.

WILLIAMS, B. Ethics and the limits of philosophy. Cambridge, Mass.: Harvard Press, 1985. Problems of the self. Cambridge, 1973

WOLF, Susan. 'Moral saints'. Journal of philosophy, 79, 1982: 419-39. 